\title{
Metabolic Profiling of Maize Mutants Deficient for Two Glutamine Synthetase Isoenzymes Using ${ }^{1} \mathrm{H}-\mathrm{NMR}$-based Metabolomics ${ }^{\dagger}$
}

\author{
Caroline Broyart, ${ }^{a, b}$ Jean-Xavier Fontaine, ${ }^{a}$ Roland Molinié, ${ }^{a}$ \\ Dominique Cailleu, ${ }^{c}$ Thérèse Tercé-Laforgue, ${ }^{b}$ Frédéric Dubois, $^{a}$ \\ Bertrand Hirel $^{\mathrm{b}}$ and François Mesnard ${ }^{\mathrm{a} *}$
}

\begin{abstract}
:
Introduction - Maize mutants deficient for the expression of two genes encoding cytosolic glutamine syntehtase (GS) isoenzymes GS1.3 and GS1.4 displayed reduced kernel number and kernel size, respectively, the effect of the mutation being cumulative in the double mutant. However, at maturity, shoot biomass production was not modified in all the mutants, indicating that the reaction catalysed by the enzyme is specifically involved in the control of grain yield.

Objective - To examine the physiological impact of the GS mutations on the leaf metabolic profile during the kernel filling period, during which nitrogen is remobilised from the shoots to be further exported to the kernels.

Methodology - An ${ }^{1} \mathrm{H}-\mathrm{NMR}$ spectroscopy metabolomic was applied to the investigation of metabolic change of the gln 1.3, gln 1.4 and $g \ln 1.3 / 1.4$ double mutant.

Results - In the three GS mutants, an increase in the amount of several N-containing metabolites such as asparagine, alanine, threonine and phophatidylcholine was observed whatever the level of nitrogen fertilisation. In addition, we found an accumulation of phenylalanine and tyrosine, two metabolites involved the primary steps of the phenylpropanoid pathway.

Conclusion - Changes in the metabolic profile of the GS mutants suggest that, when cytosolic GS activity is strongly reduced, either alternative metabolic pathways participate in the reassimilation of ammonium released during leaf protein remobilisation or that premature leaf senescence is induced when kernel set and kernel filling are affected. The accumulation of phenylalanine and tyrosine in the mutant plants indicates that lignin biosynthesis is altered, thus possibly affecting ear development. Copyright (c) 2009 John Wiley \& Sons, Ltd.
\end{abstract}

Keywords: glutamine synthetase; Zea mays; metabolomics; mutants; nuclear magnetic resonance spectroscopy

\section{Introduction}

Since the green revolution, nitrogen $(\mathrm{N})$ fertilisation has been increasingly used in agriculture to increase yield in cereals and other coarse grain crops. Nevertheless, both to avoid pollution by nitrate and to maintain a sufficient profit margin, farmers have to reduce the use of $\mathrm{N}$ fertiliser. This can be achieved by developing crop varieties that have a better nitrogen use efficiency (NUE). Thus, a better knowledge of the physiological basis and genetic basis of NUE is necessary in order to improve $\mathrm{N}$ uptake and utilisation efficiency either through conventional breeding or genetic engineering (Hirel et al., 2007). Over the last decade, it has been put forward on a regular basis that the reaction catalysed by the enzyme glutamine synthetase (GS; EC 6.3.1.2) is an important step in the control of plant productivity (Andrews et al., 2004; Gallais and Hirel, 2004; Hirel et al., 2007; Bernard and Habash, 2009). The GS enzyme catalyses an ATP-dependent conversion of glutamate to glutamine using ammonium as a substrate. Ammonium can be directly taken up from the soil or originates from a variety of physiological processes such as nitrate reduction, photorespiration, amino acid interconversion and leaf protein remobilisation (Ireland and Lea, 1999). In higher plants, GS is represented by two isoenzymes, located either in the cytosol (GS1) or in the plastids (GS2) (Hirel and Lea, 2001). GS2 is encoded by a single nuclear gene per haploid genome, whereas GS1 is encoded by a small multigene family containing up to five genes depending on the plant species examined (Cren and Hirel, 1999). For example there are five genes encoding GS1 in

\footnotetext{
* Correspondence to: F. Mesnard, Laboratoire de Phytotechnologie EA3900BioPI, Faculté de Pharmacie, 1, rue des Louvels 80037 Amiens cedex 1, France. E-mail: Francois.mesnard@u-picardie.fr

a EA 3900-BioPI Biologie des Plantes et Contrôle des Insectes Ravageurs, Faculté de Pharmacie, 1, rue des Louvels et Faculté des Sciences, 33, rue Saint Leu, 80037 Amiens cedex 1, France

b Laboratoire de la Nutrition Azotée des Plantes, UMR 511, INRA, Centre de Versailles, R.D. 10, 78026 Versailles cedex, France

Plateforme Analytique, Bâtiment Serres-Transfert, rue de Mai/rue Dallery 80039 Amiens cedex 1, France

This article is published in Phytochemical Analysis as a special issue on Metabolomics in Plant and Herbal Medicine Research, edited by Young Hae Choi, Hye Kyong Kim and Robert Verpoorte, all from Leiden University in the Netherlands.
} 
Arabidopsis (Ishiyama et al., 2004) and maize (Hirel et al., 2005), three genes encoding GS1 in wheat (Habash et al., 2007) and rice (Tabuchi et al., 2005), and two genes encoding GS1 in Medicago truncatula (Cavalho et al., 1997) and potato (Teixeira et al., 2005). Among these different GS1 isoforms, one is localised in the phloem whatever the plant examined (Tobin and Yamaya, 2001; Dubois et al., 1996; Brugière et al., 1999; Teixeira et al., 2005; Sakurai et al., 1996; Tabuchi et al., 2005; Kichey et al., 2005; Martin et al., 2006; Bernard et al., 2008). The phloem GS1 isoform is likely to be involved in the synthesis of glutamine used for longdistance transport of N-containing molecules. Another cytosolic GS isoform, which is usually also highly expressed in root tissues, is induced in the cytosol of the leaf parenchyma cells of C3 plants during leaf senescence (Brugière et al., 2000; Kichey et al., 2005; Bernard et al., 2008). This isoform of GS1 is probably involved in the recycling of ammonium released during leaf protein remobilisation from source to sink organs (Bernard and Habash, 2009; Masclaux et al., 2001). In a C4 plant such as maize, two of the five genes encoding a GS1 ( $G \ln 1-3$ and $G \ln 1-4)$ are highly expressed in most plant organs regardless of leaf age and environmental conditions (Sakakibara et al., 1992; Li et al., 1993; Limami et al., 2001; Hirel et al., 2005). Recently, it has been suggested that Gln1-4 is involved in the reassimilation of ammonium released during leaf protein degradation, whereas $G \ln 1-3$ plays a housekeeping function throughout plant growth and development (Limami et al., 2002; Hirel et al., 2005). Moreover, the importance of Gln1-3 and Gln1-4 for maize productivity has been recently emphasised using both forward and reverse genetic approaches leading Martin et al. (2006) to conclude that GS1 plays a major role in the control of kernel yield and its components but is not involved in the control of vegetative plant biomass production (Martin et al., 2006; Hirel et al., 2007). Preliminary physiological analysis of maize $\mathrm{g} \ln 1.3, \mathrm{~g} \ln 1.4$ and $\mathrm{g} \ln 1.3 / \mathrm{g} \ln 1.4$ double mutants showed that $\mathrm{N}$ metabolism is altered as the result of reduced GS1 activity in leaves (Martin et al., 2006). To further investigate both the physiological and developmental impact of the $g \ln 1.3, g \ln 1.4$ and $\mathrm{g} \ln 1.3 / \mathrm{g} \ln 1.4$ knockout mutations on plant performance, we performed a metabolomic profiling study using ${ }^{1} \mathrm{H}$-nuclear magnetic resonance (NMR) spectroscopy followed by multivariate data analysis. This technique, which is a non-targeted analytical method, is able to provide a wide range of information about the metabolite content in different organs and thus on the overall plant metabolic status in a relatively short period of time on a large number of samples (Verpoorte et al., 2007).

\section{Experimental}

\section{Plant material}

The isolation and characterisation of maize $g \ln 1-3-, g \ln 1-4-$ and $g \ln 1-$ 3/1-4- deficient mutants was previously described by Martin et al. (2006). Maize mutants and wild-type (WT) plants were grown under suboptimal $\mathrm{N}$ conditions $\left(\mathrm{N}^{+}\right)$or under $\mathrm{N}$-limiting conditions $\left(\mathrm{N}^{-}\right)$using the growth conditions used by Martin et al. (2006). The leaf below the ear was harvested at 55 days after silking. The leaf below the ear was selected since it has been shown to provide a good indication of the source-sink transition during grain filling which corresponds to the translocation of $\mathrm{N}$ and carbon assimilates from the leaf to the developing ear (Hirel et al., 2005; Martin et al., 2005, 2006). Leaf samples were harvested between 9 and 12 a.m. and frozen in liquid $\mathrm{N}_{2}$, ground to a homogenous powder using a grinder (MM301, Retsch, Germany), stored at $-80^{\circ} \mathrm{C}$ and freeze-dried. These leaf samples used for NMR analysis were the same as those used for the molecular and physiological characterisation of the GS1 deficient mutants of maize (Martin et al., 2006).

\section{Metabolite extraction}

Fifty milligrams of freeze-dried material were transferred to a $2 \mathrm{~mL}$ microtube containing $1.5 \mathrm{~mL}$ of extraction buffer composed of $750 \mu \mathrm{L}$ of $\mathrm{CH}_{3} \mathrm{OH}-d_{4}$ and $750 \mu \mathrm{L}$ of $\mathrm{D}_{2} \mathrm{O}\left(\mathrm{KH}_{2} \mathrm{PO}_{4}\right.$ buffer, $\left.\mathrm{pH} 6\right)$ containing trimethyl silyl propionic acid sodium salt (TMSP- $\left.d_{4}\right)$. The tube was shaken at room temperature for 1 min using a vortex homogeniser, then sonicated for $25 \mathrm{~min}$, and finally centrifuged at $14000 \mathrm{rpm}$ at room temperature for $30 \mathrm{~min}$. Six hundred microlitres of supernatant were then transferred into a $5 \mathrm{~mm}$ NMR tube.

\section{NMR spectra measurements}

All spectra (' ${ }^{1} \mathrm{H}-\mathrm{NMR}$, J-resolved, TOCSY and HSQC) were recorded at $300 \mathrm{~K}$ on a Bruker Avance DMX500 spectrometer operating at $500.13 \mathrm{MHz}$ for ${ }^{1} \mathrm{H}$ using a multinuclear broadband TXI $5 \mathrm{~mm}$ probe. $\mathrm{CH}_{3} \mathrm{OH}-d_{4}$ was used as the internal lock. ${ }^{1} \mathrm{H}$ NMR spectra consisted of 128 scans of $32 \mathrm{~K}$ data points with a spectral width of $5208 \mathrm{~Hz}$ and a water suppression pulse sequence with a relaxation delay of $2 \mathrm{~s}$. The resulting ${ }^{1} \mathrm{H}$ spectra were manually phased and baseline-corrected, and calibrated to TMSP at 0.0 ppm, all using XWIN NMR (version 3.3, Bruker). The FID was multiplied by an exponential weighing function corresponding to a line broadening of $0.3 \mathrm{~Hz}$ prior to Fourier transformation. Two-dimensional J-resolved NMR spectra were acquired with 1.0 s relaxation delay using 64 scans per 64 increments that were collected into $16 \mathrm{~K}$ data points, using spectral widths of $5208 \mathrm{~Hz}$ in F2 and $50 \mathrm{~Hz}$ in F1. J-resolved spectra were tilted by $45^{\circ}$ and symmetrised about F1. The TOCSY spectra were acquired using 24 scans per 512 increments that were collected into $4 \mathrm{~K}$ data points, using spectral widths of $5208 \mathrm{~Hz}$ in both dimensions. A $2.0 \mathrm{~s}$ relaxation delay and a mixing time of $60 \mathrm{~ms}$ were employed. The HSQC NMR spectra were acquired with 1.0 s relaxation delay using 128 scans per 256 increments that were collected into $2 \mathrm{~K}$ data points, using spectral widths of $5208 \mathrm{~Hz}$ in F2 and $22638 \mathrm{~Hz}$ in F1. All 2D spectrum were calibrated at 0.0 ppm to TMSP.

\section{Data analysis}

The ${ }^{1} \mathrm{H}$-NMR spectra were automatically reduced to ASCII files using MestReNova (version 5.2.5, Mestrelab Research, Santiago de Compostella, Spain). The region between $\delta 4.85$ and $\delta 4.75$ was removed from the analysis because of the residual signal of water. The residual proton signals corresponding to $\mathrm{CH}_{3} \mathrm{OH}-d_{4}(\delta 3.33$ to $\delta 3.25)$ were also removed. Spectral intensities were scaled to the total area and reduced to integrated regions or 'buckets' of equal width $(0.04 \mathrm{ppm})$ corresponding to the region of $\delta$ 10.0 to $\delta$ 0.3. The generated ASCII file was imported into Microsoft EXCEL for the addition of labels. Principal component analysis (PCA) and partial least squares discriminant analysis (PLS-DA) were performed with the SIMCA-P software (version 11.0, Umetrics, Umeå, Sweden). The scaling method for PCA was Pareto and for PLS-DA the unit-variance method was used. Each signal identified by PLS-DA as discriminant was integrated using MestReNova. The resulting area was used to test the significance of the differences observed between WT and mutants by a student test using the Excel software (Microsoft). The PLS-DA model was validated using the permutation method through 20 applications.

\section{Results and Discussion}

\section{Metabolites identification by one- and two-dimensional NMR spectra}

The ${ }^{1} \mathrm{H}-\mathrm{NMR}$ spectra of the $g \ln 1-3, g \ln 1-4$ and $g \ln 1-3 / 1-4$ mutants leaves were compared with those of the WT. A number of primary and secondary metabolites were identified in the ${ }^{1} \mathrm{H}$-NMR spectrum (Fig. 1). All metabolites were identified by comparison with chemical shifts of reference compounds. The complete assignments of the identified compounds signals were carried out by ${ }^{1} \mathrm{H}$, J-resolved, TOCSY and HSQC spectra and with 


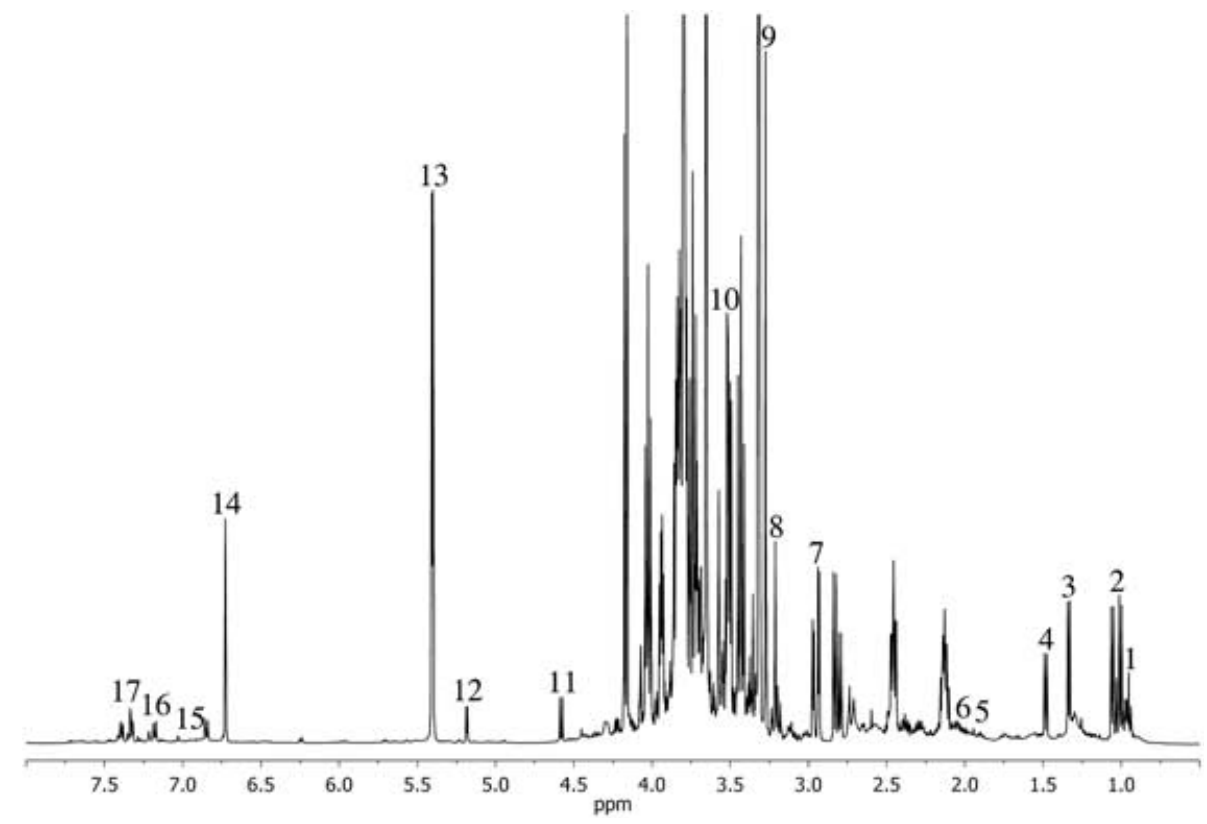

Figure 1. Representative ${ }^{1} \mathrm{H}-\mathrm{NMR}$ spectrum in the range of $\delta 0.5$ to $\delta 8.5$. (1) lleu and Leu, (2) Val, (3) Thr, (4) Ala, (5) GABA, (6) Pro, (7) Asn, (8) choline, (9) phosphatidylcholine, (10) Gly, (11) $\beta$-glucose, (12) $\alpha$-glucose, (13) sucrose, (14) fumaric acid, (15) chlorogenic acid, (16) Tyr, (17) Phe.

the comparison of reference compounds and previously reported data (Manetti et al., 2006; Castro et al., 2008; Piccioni et al., 2009). It was possible to identify the amino acids such as alanine (Ala), asparagine (Asp), glycine (Gly), isoleucine (lleu), leucine (Leu), phenyalanine (Phe), proline (Pro), threonine (Thr), tyrosine (Tyr) and valine (Val) as well as $\gamma$-aminobutyric acid (GABA). Organic acids such as fumaric acid and carbohydrates such as sucrose and glucose were also identified due to their anomeric signals and by comparison with pure compounds. By analysis of J-resolved spectra, the signals from the two trans olefinic protons of chlorogenic acid ( $\mathrm{H}-7$ at $\delta 7.60, \mathrm{H}-8$ at $\delta 6.35)$ were characterised as described previously (Leiss et al., 2009). In the ${ }^{1} \mathrm{H}-\mathrm{NMR}$ spectrum the chemical shift at $\delta 1.34$ was attributed to Thr with the help of the TOCSY spectrum. In addition, the chemical shift of the two protons at $\delta 3.50$ and at $\delta 4.22$ was the $\alpha-\mathrm{CH}$ and $\beta-\mathrm{CH}$, respectively attributed to Thr. Moreover, phospholipids such as phosphatidylcholine and nitrogenous compounds like choline were assigned with the help of HSQC. J-resolved and TOCSY spectra allowed the differentiation of Ileu and Leu. With the help of the chemical shift at $\delta 3.56$ and the doublet at $\delta 1.02$ ( $J$-resolved spectra), lleu was identified with confidence. Leu was identified by the chemical shift at $\delta 0.96, \delta 9.9$ thanks to J-resolved spectra and with the chemical shift at $\delta 3.65$ thanks to TOCSY spectra (Table 1).

Table 1. Resonance assignments of metabolites identified in NMR spectra of maize with chemicals shifts $(\delta)$ and coupling constants $(\mathrm{Hz})\left(\mathrm{CH}_{3} \mathrm{OH}-\mathrm{d}_{4}-\mathrm{KH}_{2} \mathrm{PO}_{4}\right.$ in $\left.\mathrm{D}_{2} \mathrm{O} ; \mathrm{pH} 6.0\right)$

\section{Compound}

Ala

$\alpha$-Aminobutyric acid (GABA)

Asn

Chlorogenic acid

Choline

Fumaric acid

$\beta$-Glucose

$\alpha$-Glucose

Gly

Ileu

Leu

Phe

Phosphatidylcholine

Pro

Sucrose

Thr

Tyr

Val
Chemical shifts (ppm) and coupling constants $(\mathrm{Hz})$

$1.48\left(\beta-\mathrm{CH}_{3}, \mathrm{~d}, J=7.2 \mathrm{~Hz}\right)$

$1.90\left(\beta-\mathrm{CH}_{2}, \mathrm{~m}\right), 2.36\left(\alpha-\mathrm{CH}_{2}, \mathrm{t}, J=7.2 \mathrm{~Hz}\right), 3.00\left(\gamma-\mathrm{CH}_{2}, \mathrm{t}, J=7.5 \mathrm{~Hz}\right)$

$2.82\left(\beta-\mathrm{CH}_{2}, \mathrm{dd}, J=17.0,8.1 \mathrm{~Hz}\right), 2.95\left(\beta^{\prime}-\mathrm{CH}_{2}, \mathrm{dd}, J=17.0,4.0 \mathrm{~Hz}\right), 3.94(\alpha-\mathrm{CH}, \mathrm{dd}, J=8.2,4.0 \mathrm{~Hz})$

$6.35(\mathrm{H}-8, \mathrm{~d}, J=16.0 \mathrm{~Hz}), 6.87(\mathrm{H}-5, \mathrm{~d}, J=8.2 \mathrm{~Hz}), 7.05(\mathrm{H}-6, \mathrm{dd}, J=8.3,1.9 \mathrm{~Hz}), 7.13(\mathrm{H}-2, \mathrm{~d}$,

$J=1.9 \mathrm{~Hz}), 7.60(\mathrm{H}-7, \mathrm{~d}, J=15.9 \mathrm{~Hz})$

$3.21\left(\mathrm{CH}_{3}, \mathrm{~s}\right)$

$6.73(\mathrm{H}-2$ and $\mathrm{H}-3, \mathrm{~s})$

$4.57(\mathrm{H}-1, \mathrm{~d}, J=7.9 \mathrm{~Hz})$

$5.17(\mathrm{H}-1, \mathrm{~d}, J=3.8 \mathrm{~Hz})$

$3.57\left(\alpha-\mathrm{CH}_{2}, \mathrm{~s}\right)$

$0.95(\delta-\mathrm{CH} 3, \mathrm{t}, J=7.4 \mathrm{~Hz}), 1.02(\gamma-\mathrm{CH} 3 \mathrm{~d}, J=7.0 \mathrm{~Hz}), 3.56(\alpha-\mathrm{CH}, \mathrm{d}, J=4.0 \mathrm{~Hz})$

$0.96\left(\delta-\mathrm{CH}_{3}, \mathrm{~d}, J=6.6 \mathrm{~Hz}\right), 0.98\left(\delta^{\prime}-\mathrm{CH}_{3}, \mathrm{~d}, J=6.6 \mathrm{~Hz}\right), 3.65(\alpha-\mathrm{CH}, \mathrm{m})$

7.3 to $7.4(\mathrm{H}-2, \mathrm{H}-3, \mathrm{H}-4, \mathrm{H}-5$, and $\mathrm{H}-6, \mathrm{~m})$

$3.27\left(\mathrm{CH}_{3}, \mathrm{~s}\right)$

$2.00\left(\gamma-\mathrm{CH}_{2}, \mathrm{~m}\right), 4.06(\alpha-\mathrm{CH}, \mathrm{dd}, J=8.7,6.3 \mathrm{~Hz})$

$4.16(\mathrm{H}-3$ of fructose moeity, $\mathrm{d}, J=8.6 \mathrm{~Hz}), 5.40(\mathrm{H}-1$ of glucose moiety, $\mathrm{d}, J=3.8 \mathrm{~Hz})$

$1.34\left(\gamma-\mathrm{CH}_{3}, \mathrm{~d}, J=6.6 \mathrm{~Hz}\right), 3.50(\alpha-\mathrm{CH}, \mathrm{d}, J=5.2 \mathrm{~Hz}), 4.22(\beta-\mathrm{CH}, \mathrm{m})$

$6.85(\mathrm{H}-2$ and $\mathrm{H}-6, \mathrm{~m}), 7.18(\mathrm{H}-3$ and $\mathrm{H}-5$, ring, $\mathrm{m})$

$1.00\left(\gamma-\mathrm{CH}_{3}, \mathrm{~d}, J=7.0 \mathrm{~Hz}\right), 1.05\left(\gamma-\mathrm{CH}_{3}, \mathrm{~d}, J=7.0 \mathrm{~Hz}\right)$ 


\section{Data analysis}

In order to select the resonances corresponding to metabolite content that was altered in the $g \ln 1.3, g \ln 1.4$ and $g \ln 1.3 / 1.4$ mutants, multivariate data analysis were performed. Indeed, metabolomics experiments produce a large set of data. For a first overview of metabolomic changes, multivariate analysis can deal with a large data set by reducing the dimensionality of the ${ }^{1} \mathrm{H}-\mathrm{NMR}$ data. Principal component analysis is an unsupervised method which reduces the dimensionality of a given data set by producing new linear combinations of the original variables. PCA allows the visualisation of trends, clustering, similarity/dissimilarity among the samples, thus giving a macroscopic metabolic differentiation within evaluated samples (Leiss et al., 2009). For this, raw NMR data have to be bucketed in order to align the signals and avoiding possible fluctuations. The signals in the region between $\delta 0.3$ and $\delta 10.0$ were bucketed every 0.04 ppm, generating 242 discrete chemical shift regions to produce a series of sequentially integrated regions. After residual signals from water and methanol- $d_{4}$ were suppressed, 235 variables were submitted to PCA analysis and thus reduced to a few principal components. This explains the variation among the samples in terms of metabolic changes. However, it was not possible to discriminate correctly the three GS1 mutants from the WT (data not shown), indicating that the biological variations within the samples of the same groups could be higher than between groups. In this case, a supervised multivariate data analysis using covariance is required to try to associate a group of metabolites to the mutation. Partial least square discriminant analysis corresponds to such a supervised method. In contrast to PCA, which only uses the information of the metabolomic matrix, PLS-DA also takes into account the matrix of the plant type. PLS-DA uses a discrete class matrix (in this case 0 for the GS1 mutants and 1 for WT). The separation of PLS-DA is achieved by the covariance of the two datasets. With PLS-DA, the separation between WT and the three maize GS1 mutants was considerably improved (Fig. 2A). The permutation test through 20 applications for the wild-type group (Fig. 2C) and mutant group (Fig. 2D) validated the PLS-DA model. Indeed, all Q2 values of permuted $Y$ vectors were lower than the original ones and the regression of $\mathrm{Q} 2$ lines intersected the $y$-axis at below zero (Fig. $2 \mathrm{C}$ and D), indicating that the model was valid (Leiss et al., 2009 citing Eriksson et al., 2001).

In accordance with the loading plot (Fig. 2B), Asp, sucrose, glucose and Phe were assigned to the maize GS1 mutants by comparison with the WT. The WT was characterised by a high content of Ileu, GABA and Pro. The $t$-test applied to the data defined the statistically significant variables found between the mutants and the WT. From the $235^{1} \mathrm{H}-\mathrm{NMR}$ variables 49 were significantly different $(p<0.05)$. Among these variables, signals for Asp, sucrose, glucose, Tyr, chlorogenic acid, Ileu GABA and Pro, which were identified by PLS-DA, were confirmed as differentiating significantly the two groups of samples.

\section{Metabolite ratio analysis}

Since overlapping can occur in $1 \mathrm{D}-{ }^{1} \mathrm{H}-\mathrm{NMR}$ spectra, data obtained by buckets for PLS-DA analysis can be biased. Therefore,
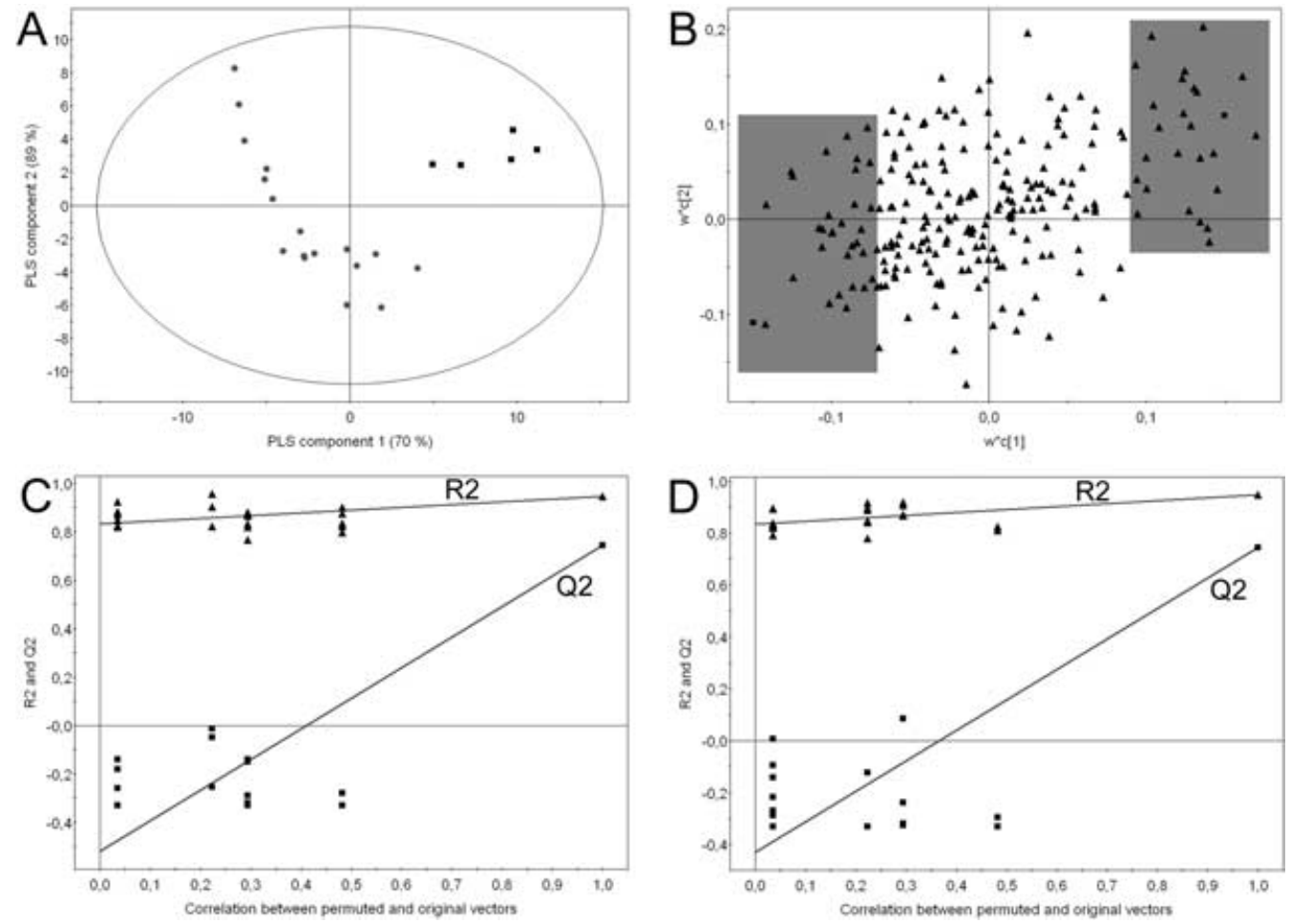

Figure 2. (A) Score plot of PLS-DA of crude extracts from maize leaves of WT $(v)$ and cytosolic GS mutants ( $\lambda$ ). (B) Loading plot of PLS-DA in leaves using two classes (class 0 , WT; class 1, cytosolic GS mutant). Each triangle $(\sigma)$ represents the chemical shifts from bucketed ${ }^{1} \mathrm{H}$ NMR data. The grey frames show the discriminant chemical shifts of Asn, $\alpha$-glucose, $\beta$-glucose, sucrose, tyrosine and phenylalanine contained in cytosolic GS mutant (on the bottom left) and lleu GABA and Pro contained in WT (on the top right). (C) and (D) represent permutation validation (20 permutations with three components) plot for the mutant group (C) and the susceptible group (D) of PLS-DA based on ${ }^{1} \mathrm{H}$-NMR spectra. In this validation plot R2 stands for variance and Q2 stands for predictive ability of the model. Leaf samples were harvested at maturity on plants grown under $\mathrm{N}$ suboptimal conditions. 
$J$-resolved spectra were used to detect individualised signals of identified discriminant metabolites. A $t$-test was then applied to the area corresponding to these signals in order to determine statistically significant signals between the three GS1 mutants and the WT. The area was integrated and the spectra scaled to the total area or to TMSP area using MestReNova. These two integration methods gave the same results except for Thr, Ala, choline and phosphatidylcholine which were found to be discriminant with TMSP area correction. Most of the metabolites were confirmed as significantly different $(p<0.05)$ in the two groups separately (i.e. $\mathrm{N}^{+}$or $\mathrm{N}^{-}$) or together (i.e. $\mathrm{N}+$ and $\mathrm{N}^{-}$) (Table 2). Those metabolites were visible on the loading plot, where plots corresponding to the area of Thr, Ala and phosphatidylcholine were found in the GS1 mutants (bottom left) and a plot corresponding to choline was found in the WT (top right), (Fig. 2B). In addition, the same scale of variation in metabolite content was observed between the mutants and the WT independently of the $\mathrm{N}$ fertilisation regime $\left(\mathrm{N}^{+}\right.$or $\left.\mathrm{N}^{-}\right)$, except for fumaric acid, choline, Gly and Val, as reported in Table 2. Indeed fumaric acid, choline and Gly contents were higher in the WT in $\mathrm{N}^{+}$, whereas the Val content was lower in $\mathrm{N}^{-}$, which was the opposite in the mutants.

In this study, it was possible to observe a number of differences between the metabolic profiles of three different maize mutants deficient for cytosolic GS (namely $g \ln 1.3, g \ln 1.4$ and $g \ln 1.3 / 1.4$ double mutant) and the WT. This indicates that, although the two isoforms GS1.3 and GS1.4 play a non-redundant function in the synthesis of Glu (Martin et al., 2006), a number of metabolic functions associated with ammonium assimilation are commonly altered in the three GS mutants. These differences were assigned to particular metabolic pathways that were likely to play a compensatory role in the mutants, to circumvent the lack of GS activ- ity in the cytosol. It has been generally observed that the enzyme activity remains relatively high in mature leaves of maize compared with younger leaves or other organs (Hirel et al., 2005; Limami et al., 2002; Cañas et al., 2009). During grain filing, large amounts of ammonium are released in senescing leaves presumably as a result of chloroplastic protein hydrolysis (Hörtensteiner and Feller, 2002). The released ammonium is reassimilated into GIn through the reaction catalysed by GS. In the three GS mutants we observed a marked increase in Asp in agreement with previously published results (Martin et al., 2006; Table 2). Under standard physiological conditions, Asn rarely accumulates, unless the plant is subjected to biotic or abiotic stresses. Large quantities of Asn can also be produced during seed germination or when reduced $\mathrm{N}$ is remobilised and transported from source to sink organs (Lea et al., 2007). Interestingly, an accumulation of Asn was observed previously when GS activity was impaired in the nodules of temperate legumes (Carvalho et al., 2003; Harrison et al., 2003; Wong et al., 2004). This result suggested that other enzymes such as asparagine synthetase (AS; EC 6.3.5.4) play an important role in by-passing the flux of reduced $\mathrm{N}$ to avoid the accumulation of ammonium that is a prerequisite for plant survival (Fig. 3). Because the number of kernels is reduced in the GS mutants, one cannot also rule out the possibility that premature leaf senescence accompanied by an increase in Asn, is occurring, thus mimicking the well-known effect of ear removal on plant development (Christensen et al., 1981). In line with the former hypothesis, we observed an increase in a variety of nitrogenous compounds such as Ala, Phe, Thre, Tyr and phophatidylcholine independently of the level of $\mathrm{N}$ fertilisation. The biosynthesis of all of these compounds is also a means for storing reduced $\mathrm{N}$ (Fig. 3). This observation fits with the current hypothesis that when other sources of reduced $\mathrm{N}$ than Gln (usually used for long

Table 2. Results (ratios from the WT to the three GS mutants) of selected compound signals from ${ }^{1} \mathrm{H}$-NMR spectra obtained with extracts of maize leaves situated below the ear. Plants were grown either under high $\mathrm{N}\left(\mathrm{N}^{+}\right)$or low $\mathrm{N}\left(\mathrm{N}^{-}\right)$fertilisation conditions and the leaf material harvested 55 days after silking (Martin et al., 2006)

\begin{tabular}{|c|c|c|c|c|}
\hline \multirow[t]{2}{*}{ ppm } & \multirow[t]{2}{*}{ Compound } & \multicolumn{3}{|c|}{ Maturity } \\
\hline & & $\mathrm{N}^{+}$and $\mathrm{N}^{-}$ & $\mathrm{N}^{+}$ & $\mathrm{N}^{-}$ \\
\hline $0.94-0.95$ & lleu & $1,41^{*}$ & $1,46^{* *}$ & $1,25^{*}$ \\
\hline $0.97-0.99$ & Leu & 1,29 & 1,17 & $1,36^{* *}$ \\
\hline $0.99-1.01$ & Val & 0,76 & $0,48^{*}$ & $1,68 * *$ \\
\hline $1.32-1.35$ & Thr & 0,84 & 0,77 & $0,87 * *$ \\
\hline $1.45-1.50$ & Ala & 0,76 & $0,71^{*}$ & 0,69 \\
\hline $1.86-1.92$ & GABA & $1,68 *$ & 1,39 & $1,86^{* * *}$ \\
\hline $1.99-2.09$ & Pro & $1,32^{* * *}$ & $1,37^{*}$ & $1,27^{*}$ \\
\hline $2.92-2.98$ & Asn & $0,48^{*}$ & $0,30 *$ & 1,00 \\
\hline $3.20-3.22$ & Choline & 1,21 & 1,32 & $0,78 * *$ \\
\hline $3.25-3.28$ & Phospatidylcholine & 0,60 & $0,59 *$ & $0,37 * *$ \\
\hline $3.54-3.59$ & Gly & 1,09 & $1,54^{*}$ & $0,82^{*}$ \\
\hline $4.56-4.60$ & $\beta$-Glucose & $0,66^{* *}$ & 0,69 & $0,61 *$ \\
\hline $5.17-5.20$ & $\alpha$-glucose & $0,57^{* *}$ & 0,63 & $0,49 *$ \\
\hline $5.38-5.42$ & Sucrose & $0,67^{*}$ & 0,76 & $0,56^{* *}$ \\
\hline $6.66-6.75$ & Fumaric acid & 1,18 & $1,77^{*}$ & 0,88 \\
\hline $6.86-6.90$ & Chlorogenic acid & 1,01 & $1,32^{*}$ & 1,05 \\
\hline $7.17-7.20$ & Tyr & $0,48^{* * *}$ & $0,52^{* *}$ & 0,87 \\
\hline $7.31-7.45$ & Phe & $0,43^{* *}$ & $0,36^{*}$ & 0,94 \\
\hline
\end{tabular}




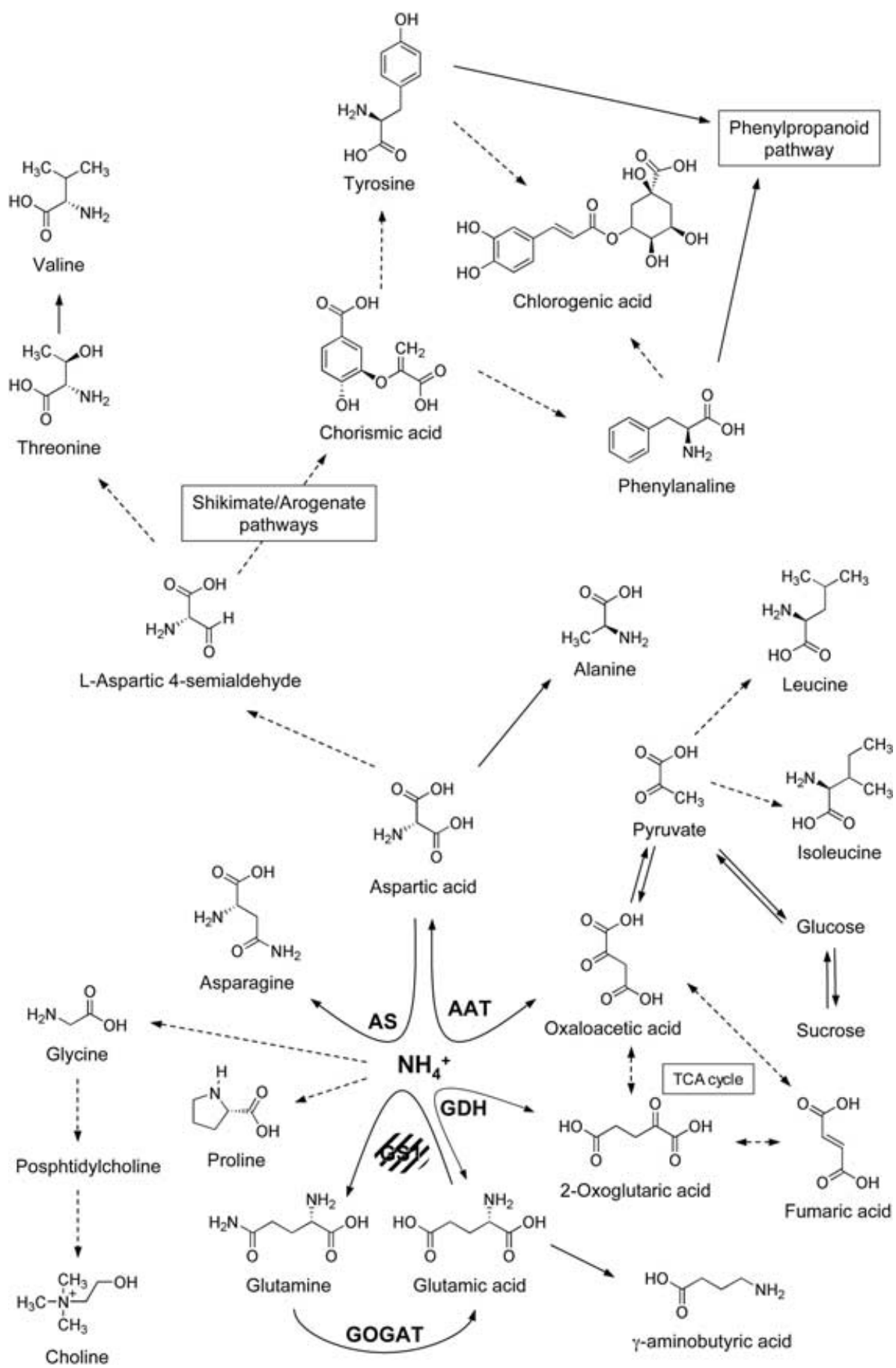

Figure 3. Metabolic pathways modified in the maize mutants deficient for cytosolic GS. Enzyme abbreviations: AAT, aspartate aminotransferase; AS, asparagine synthetase; GDH, glutamate dehydrogenase; GOGAT, glutamate synthase; GS1, cytosolic glutamine synthethase.

distance transport in cereals (Miflin and Habash, 2002), cannot be exported to the developing ear, both kernel set and kernel filling are altered (Martin et al., 2006; Hirel et al., 2007).

It is worth noting that although there is an accumulation of reduced $\mathrm{N}$, as form of amino acids in the mutants, the level of Glu as not markedly modified. It is well established that plants maintain their relative Glu concentration within fairly narrow limits (Forde and Lea, 2007; Labboun et al., 2009). One can hypothesise that the homoeostasis of Glu in maintained in the GS mutants through the activity of metabolic pathways that are able to syn- thesise or catabolise the amino acid. In the GS1 mutants, modifications in the ammonium assimilatory pathway could also involve the shikimate/arogenate pathway, as shown by the increase in their Phe and Tyr contents (Table 2). Deamination of Phe and Tyr, leading to the release of ammonium, is the first step of the phenylpropanoid pathway at the origin of lignin formation (Fig. 3). Lignification is a process during which $\mathrm{N}$ recycling and thus cytosolic GS play a major role (Whetten and Sederoff, 1995; Cánovas et al., 2007). If the GS1-3 and GS1-4 isoenzymes are specifically expressed during ear development which requires 
the synthesis of large amounts of lignin (Reeves, 1950), the ammonium released during this developmental process could not be reassimilated, thus perturbing its formation. The observation that the length of the ear in the GS1 mutants is shorter is in favour of this hypothesis (Martin et al., 2006). In conclusion, this detailed metabolic profiling study revealed that the role of GS1 in maize for the control of kernel yield may be more complex than originally described since ammonium can be released by a variety of metabolic pathways both in vegetative and reproductive organs (Hirel and Lea, 2001; Cañas et al., 2009). Further metabolomic and molecular genetic studies are therefore required to investigate the impact of a GS1 mutation in reproductive tissues and to determine if there is a regulatory control mechanism, mediated by the synthesis of Glu, and occurring between the leaves and the developing ear.

\section{Acknowledgements}

The authors wish to thank Dr. Hye Kyong Kim, Dr. Young Hae Choi and Professor Robert Verpoorte from the University of Leiden for very helpful discussions.

\section{References}

Andrews M, Lea PJ, Raven JA, Lindsey K. 2004. Can genetic manipulation of plant nitrogen assimilation enzymes result in increased crop yield and greater N-use efficiency? An assessment. Ann Appl Biol 145: 25-40.

Bernard SM, Habash DZ. 2009. The importance of cytosolic glutamine synthetase in nitrogen assimilation and recycling. New Phytol 182: 608-620.

Bernard SM, Møller ALB, Dionisio G, Kichey T, Jahn TP, Dubois F, Baudo M, Lopes MS, Tercé-Laforgue T, Foyer CH, Parry MAJ, Forde BG, Araus JL, Hirel B, Schjoerring JK, Habash DZ. 2008. Gene expression, cellular localisation and function of glutamine synthetase isozymes in wheat (Triticum aestivum L.). Plant Mol Biol 67: 89-105.

Brugière $N$, Dubois F, Limami AM, Lelandais $M$, Roux $Y$, Sangwan RS, Hirel B. 1999. Glutamine synthetase in the phloem plays a major role in controlling proline production. Plant Cell 11: 1995-2012.

Brugière N, Dubois F, Masclaux C, Sangwan RS, Hirel B. 2000. Immunolocalization of glutamine synthetase in senescing tobacco (Nicotiana tabacum L.) leaves suggests that ammonia assimilation is progressively shifted to the mesophyll cytosol. Planta 211: 519-527.

Cañas RA, Quilleré I, Christ A, Hirel B. 2009. Nitrogen metabolism in the developing ear of maize (Zea mays L.): analysis of two lines contrasting in their mode of nitrogen management. New Phytol 184: 340-352.

Cánovas FM, Avila C, Cantón FR, Cañas RA, de la Torre F. 2007. Ammonium assimilation and amino acid metabolism in conifers. $J$ Exp Bot $\mathbf{5 8}$ 2307-2318.

Carvalho H, Sunkel C, Salema R, Cullimore JV. 1997. Heteromeric assembly of the cytosolic glutamine synthetase polypeptides of Medicago truncatula: complementation of a glnA Escherichia coli mutant with a plant domain-swapped enzyme. Plant Mol Biol 35: 623-632.

Carvalho HG, Lopes-Cardoso IA, Lima LM, Melo PM, Cullimore JV. 2003. Nodule-specific modulation of glutamine synthetase in transgenic Medicago truncatula leads to inverse alterations in asparagine synthetase expression. Plant Physiol 133: 243-252.

Castro C, Motto M, Rossi V, Manetti C. 2008. Variation of metabolic profiles in developing maize kernels up- and down-regulated for the hda101 gene. J Exp Bot 59: 3913-3924.

Cren M, Hirel B. 1999. Glutamine synthetase in higher plants regulation of gene and protein expression from the organ to the cell. Plant Cell Physiol 40: 1187-1193.

Christensen LE, Below FE, Hageman RH. 1981. The effects of ear removal on senescence and metabolism of maize 1. Plant Physiol 68: 1180-1185.

Dubois F, Brugière N, Sangwan RS, Hirel B. 1996. Localization of tobacco cytosolic glutamine synthetase enzymes and the corresponding transcripts shows organ- and cell-specific patterns of protein synthesis and gene expression. Plant Mol Biol 31: 803-817.
Eriksson L, Johansson E, Kettaneh-Wold N, Wold S. 2001. Multi- and Megavariate Data Analysis: Principles and Applications. Umetrics: Umeå.

Forde BG, Lea PJ. 2007. Glutamate in plants: metabolism, regulation, and signalling. J Exp Bot 58: 2339-2358.

Gallais A, Hirel B. 2004. An approach to the genetics of nitrogen use efficiency in maize. J Exp Bot 55: 295-306.

Habash DZ, Bernard S, Schondelmaier J, Weyen J, Quarrie SA. 2007. The genetics of nitrogen use in hexaploid wheat: $\mathrm{N}$ utilisation, development and yield. Theor App/ Genet 114: 403-419.

Harrison J, Pou de Crescenzo MA, Sené O, Hirel B. 2003. Does lowering glutamine synthetase activity in nodules modify nitrogen metabolism and growth of Lotus japonicus? Plant Physiol 133: 253-262.

Hirel B, Lea P. 2001. Ammonium assimilation. In Plant Nitrogen, Lea PJ, Morot-Gaudry JF (eds). Springer: Berlin; 79-99.

Hirel B, Martin A, Tercé-Laforgue T, Gonzalez-Moro MB, Estavillo JM. 2005. Physiology of maize I: A comprehensive and integrated view of nitrogen metabolism in a C4 plant. Physiol Plant 124: 167-177.

Hirel B, Le Gouis J, Ney B, Gallais A. 2007. The challenge of improving nitrogen use efficiency in crop plants: towards a more central role for genetic variability and quantitative genetics within integrated approaches. J Exp Bot 58: 2369-2387.

Hörtensteiner S, Feller U. 2002. Nitrogen metabolism and remobilization during senescence. J Exp Bot 53: 927-937.

Ireland RJ, Lea PJ. 1999. The enzymes of glutamine, glutamate, asparagine and aspartate metabolism. In Plant Amino Acids: Biochemistry and Biotechnology, Singh BK (ed.). Marcel Dekker: New York; 49-110.

Ishiyama K, Inoue E, Watanabe-Takahashi A, Obara M, Yamaya T, Takahashi H. 2004. Kinetic properties and ammonium-dependent regulation of cytosolic isoenzymes of glutamine synthetase in Arabidopsis. J Biol Chem 279: 16598-16605.

Kichey T, Le Gouis J, Sangwan B, Hirel B, Dubois F. 2005. Changes in the cellular and subcellular localization of glutamine synthetase and glutamate dehydrogenase during flag leaf senescence in wheat (Triticum aestivum L.). Plant Cell Physiol 46: 964-974.

Labboun S, Tercé-Laforgue T, Roscher A, Bedu M, Restivo FM, Velanis CN, Skopelitis DS, Moshou PN, Roubelakis KA, Suzuki A, Hirel B. 2009. Resolving the role of plant glutamate dehydrogenase: I. In vivo real time nuclear magnetic resonance spectroscopy experiments. Plant Cell Physiol 50: 1761-1773.

Lea P, Sodek L, Parry M, Shewry P, Halford N. 2007. Asparagine in plants. Ann Appl Biol 150: 1-26.

Leiss KA, Maltese F, Choi YH, Verpoorte R, Klinkhamer PGL. 2009. Identification of chlorogenic Acid as a resistance factor for thrips in chrysanthemum. Plant Physiol 150: 1567-1575.

Li MG, Villemur R, Hussey PJ, Silflow CD, Gantt JS, Snustad DP. 1993. Differential expression of six glutamine synthetase genes in Zea mays. Plant Mol Biol 23: 401-407.

Limami AM, Rouillon C, Glevarec G, Gallais A, Hirel B. 2002. Genetic and physiological analysis of germination efficiency in maize in relation to nitrogen metabolism reveals the importance of cytosolic glutamine synthetase. Plant Physiol 130: 1860-1870.

Manetti C, Bianchetti C, Casciani L, Castro C, Cocco MED, Miccheli A, Motto M, Conti F. 2006. A metabonomic study of transgenic maize (Zea mays) seeds revealed variations in osmolytes and branched amino acids. J Exp Bot 57: 2613-2625.

Martin A, Belastegui-Macadam X, Quilleré I, Floriot M, Valadier MH, Pommel B, Andrieu B, Donnison I, Hirel B. 2005. Nitrogen management and senescence in two maize hybrids differing in the persistence of leaf greenness. Agronomic, physiological and molecular aspects. New Phytol. 167: 483-492.

Martin A, Lee J, Kichey T, Gerentes D, Zivy M, Tatout C, Dubois F, Balliau T, Valot B, Davanture M, Tercé-Laforgue T, Quilleré I, Coque M, Gallais A, Gonzalez-Moro MB, Bethencourt L, Habash DZ, Lea PJ, Charcosset A, Perez P, Murigneux A, Sakakibara H, Edwards KJ, Hirel B. 2006. Two cytosolic glutamine synthetase isoforms of maize are specifically involved in the control of grain production. Plant Cell 18: 3252-3274.

Masclaux C, Quilleré I, Gallais A, Hirel B. 2001. The challenge of remobilization in plant nitrogen economy. A survey of physio-agronomic and molecular approaches. Ann Appl Biol 138: 69-81.

Miflin BJ, Habash DZ. 2002. The role of glutamine synthetase and glutamate dehydrogenase in nitrogen assimilation and possibilities for improvement in the nitrogen utilization of crops. $J$ Exp Bot 53: 979-987. 
Piccioni F, Capitani D, Zolla L, Mannina L. 2009. NMR metabolic profiling of transgenic maize with the Cry1A(b) gene. J Agric Food Chem 57: 6041-6049.

Reeves RG.1950. Morphology of the ear and tassel of maize. Am J Bot 37: 697-704.

Sakakibara H, Kawabata S, Hase T, Sugiyama T. 1992. Differential effects of nitrate and light on the expression of glutamine synthetases and ferredoxin-dependent glutamate synthase in maize. Plant Cell Physiol 33: 1193-1198.

Sakurai N, Hayakawa T, Nakamura T, Yamaya T. 1996. Changes in the cellular localization of cytosolic glutamine synthetase protein in vascular bundles of rice leaves at various stages of development. Planta 200: 306-311.

Tabuchi M, Sugiyama K, Ishiyama K, Inoue E, Sato T, Takahashi H, Yamaya T. 2005. Severe reduction in growth rate and grain filling of rice mutants lacking OsGS1;1, a cytosolic glutamine synthetase 1;1. Plant J 42: 641-651.

Teixeira J, Pereira S, Cánovas F, Salema R. 2005. Glutamine synthetase of potato (Solanum tuberosum L. cv. Desiree) plants: cell- and organspecific expression and differential developmental regulation reveal specific roles in nitrogen assimilation and mobilization. J Exp Bot 56: 663-671.

Tobin AK, Yamaya T. 2001. Cellular compartmentation of ammonium assimilation in rice and barley. J Exp Bot 52: 591-604.

Verpoorte R, Choi YH, Kim HK. 2007. NMR-based metabolomics at work in phytochemistry. Phytochem Rev 6: 3-14.

Whetten R, Sederoff R. 1995. Lignin biosynthesis. Plant Cell 7: 1001-1013.

Wong HK, Chan HK, Coruzzi GM, Lam HM. 2004. Correlation of ASN2 gene expression with ammonium metabolism in Arabidopsis. Plant Physiol 134: 332-338. 